auch einen um die Hälfte reichern Körnerertrag gaben. als der gewöhnliche Reis in vorbereitetem Boden, nämlich 150 Körner auf eine Aehre. (Univers. 1847. No.38.) B.

\title{
Mittel gegen den Kornbrand.
}

Nach Angelis Mortier zu Ypres, ist ein aus gleichen Theilen gelöschten Kalks, Schwefels und Alauns bestehendes Pulver gegen den Kornbrand, allen andern zu diesem Zweck gebrauchten Mitteln, als Zink- und Kupfersalzen, weit vorzuziehen; zahlreiche von Oeconomen 7 Jahr hindurch angestellte Versuche haben es bestätigt.

Beim Zusammenmengen dieser 3 Substanzen findet Entwickelung von Wärme statt, wahrscheinlich weil sich in dem Gremenge noch ungelöschte Kalktheile befinden; auch bemerkt man (wegen vorhandenen Ammoniakalauns) zuweilen Ammoniakgeruch.

Zwei Unzen dieses Pulvers reichen hin, um ungefähr einen Himpten Getraides damit zu beizen, d. $h$. wenn sie mit so vielem Wasser gekocht werden als nöthig ist, um gedachtes Maass damit zu tränken.

Uebrigens lässt man jeden Tag nur soviel Korn einweichen, als davon gesäet werden soll, indem die eingesogene Beize nach längerer Zeit schädlich auf das Keimungsvermögen jenes einwirken würde.

Herr Angelis Mortier schreibt die Wirkung des Pulvers dem in demselben entstehenden Kalksulfurete zu. (Journ. de Pharm. d'Anvers. Octobre 1847.) du Mênil.

\section{Einfluss der Eisensalze auf die Pflanzenvegetation.}

Die von E. Gris schon vor längerer Zeit beobachtete wohlthätige Einwirkung verdiinnter Eisenvitriollösungen auf gesunde sowohl, wie auf bleichsüchtige oder überhaupt kränkelnde Pflanzen hat sich bei weitern Versuchen vollkommen bestätigt. Zur Wurzelaufsaugung dient eine Lösung von 1 bis $1 \frac{1}{2}$ Quentchen Eisenvitriol in 1 Pfd. Wasser; zum Eintauchen für Blätter und $\mathrm{Z}$ weige ist diese Lösung noch mit $4-6 \mathrm{mal}$ so viel Wasser zu verdünnen. Ein Ast von einer kränkelnden Pflanze in die Lösung getaucht, zeigt oft schon nach 6-8 Tagen eine lebhaftere Farbe und kräfliges Wachsthum. Eben so wohlthätig ist die Wirkung auf gesunde Pflanzen, namentlich für Topfgewächse, die dadurch zugleich die Fähigkeit erlangen sollen, der' sengenden Wirkung der Sonnenstrahlen besser zu widerstehen. Eine nachtheilige Folge konnte selbst bei Jahre lang fort- 